\title{
Task shifting in dermatology: Are nurses prepared and willing?
}

\author{
Kavita Kavita', Hitaishi Mehta², Sandhya Ghai', Aarti Garg', Tarun Narang² \\ ${ }^{I}$ National Institute of Nursing Education, Postgraduate Institute of Medical Education and Research, Chandigarh, India, \\ ${ }^{2}$ Department of Dermatology, Venereology, and Leprology, Postgraduate Institute of Medical Education and Research, \\ Chandigarh, India
}

Corresponding author: Tarun Narang, MD, MNAMS. E-mail: narangtarun@yahoo.co.in

\begin{abstract}
Background: The high burden of skin diseases and the shortage of dermatologists are significant challenges in providing care to millions of people with skin diseases. Task shifting to nurses is a viable option for the delivery of dermatologic care in resource-poor settings. Satisfactory knowledge and a positive attitude are crucial for nurses to undertake the task of managing common skin diseases. This study aimed to investigate the knowledge of registered nurses and their attitude toward common skin conditions. Methods: In this descriptive, cross-sectional study, a total of 187 nurses were included from a nurses training institute by total enumeration sampling. A knowledge questionnaire and fivepoint Likert type-attitude scale were developed, validated, and employed to collect data. Written informed consent was obtained from the participants after approval from the institute ethics committee. Results: The mean of the knowledge scores were $10.7 \pm 2.2$. Nearly two thirds $(62 \%)$ of the subjects demonstrated a low level of knowledge, while the remaining $38 \%$ showed a moderate level. There was no participant in the high-knowledge category. A majority of the nurses demonstrated a favorable attitude toward learning and undertaking the task of managing common skin conditions. Conclusion: We observed a low level of knowledge on diagnosing and managing common skin conditions. We recommend incorporating the relevant concepts of common skin conditions in the nursing curriculum with an emphasis on continuing education.
\end{abstract}

Keywords: Nurses; Common skin conditions; Knowledge; Attitude; Dermatology training; Task shifting

\section{INTRODUCTION}

Skin diseases constitute a significant burden worldwide. As per the 2017 study on the global burden of disease (GBD), these contributed $1.76 \%$ of the total global burden of disease measured in DALYs (disabilityadjusted life years) [1]. Skin diseases are among the top ten causes of non-fatal disease burdens. According to 2017 GBD data, the years lived with disability (YLDs) from skin diseases worldwide were 41.6 million, which is more than with cardiovascular diseases (35.6 million) [2,3]. Skin diseases are among the top ten causes of non-fatal disease burdens in India, and the burden due to skin diseases has increased from 4.07 million in 1990 to 6.26 million in 2017 [4].
The high need for dermatological care in India poses a significant challenge to the healthcare delivery system, which already has a shortage of dermatologists. The population ratio of dermatologists is more skewed in low- and middle-income countries than in highincome countries. There are 3.2 dermatologists per 100,000 individuals in many states of the U.S. [5], compared to less than one dermatologist per 100,000 individuals in India [6]. Task shifting may be one of the solutions to increase access to dermatological care. Task shifting means transferring clinical tasks from physicians to trained non-physician health workers. Although task shifting is being done to a limited extent in dermatology, its need and effectiveness are evident from the literature [7-10]. 
Task shifting may involve various categories of nonphysician health workers, but nurses are the ideal choice. In the developed world, nurses work successfully as dermatological nurses in both independent and dependent roles $[11,12]$. India's national leprosy elimination program is an excellent example of task shifting [13]. Mid-level health care providers (MLHP) under the Ayushman Bharat scheme are also nurses who are being trained to work independently in health and wellness centers [14].

However, nurses' educational level, competence, and willingness are crucial prerequisites for successful task shifting. To the best of our knowledge, there have been no studies assessing nurses from India for their knowledge and attitude regarding skin conditions. For this reason, the present study was undertaken to evaluate the knowledge and attitude of registered nurses regarding the diagnosis and management of common skin diseases. The findings of this study will help to make recommendations for effective task shifting and curriculum changes.

\section{METHODOLOGY}

A descriptive, cross-sectional design was adopted for this study. Nurses were recruited from a nurses' training institute in Northern India. All registered nurses $(\mathrm{n}=187)$ pursuing higher education (B.Sc. nursing (post-basic)/M.Sc. nursing) were recruited in the study.

\section{Study Instruments}

A knowledge questionnaire and a five-point Likert scale were employed to assess the nurses' knowledge about and attitudes to common skin conditions. Tools were developed by reviewing the literature and consulting experts in the field of dermatology and nursing. The validation of the tools was performed by experts in the field of dermatology and nursing. Their suggestions were incorporated in the final version of the tool. The knowledge questionnaire consisted of two sections. Section I included the socio-demographic and professional profiles of the participants. Section II consisted of multiple-choice questions related to the diagnosis and management of common skin diseases. The total score ranged from 0 to 20. A higher score represented a higher level of knowledge. Knowledge scores were graded into three levels. Scores between 16 and 20 (> 80\%) were classified as a high level of knowledge, while scores between 10 and $15(79-50 \%)$ and $<10(<50 \%)$ were graded as a moderate and low level of knowledge, respectively.

A five-point Likert scale (strongly disagree, disagree, neutral, agree, strongly agree) was constructed to assess the attitude of nurses regarding the diagnosis and management of common skin disorders. There were a total of twelve statements with scores ranging from 12 to 60 . A higher score indicated a more favorable attitude. A score above the median was considered a positive attitude and below the median a negative attitude.

Data entry and analysis were performed using the software SPSS, version 20. Descriptive statistics were employed to analyze the data, and the results were presented as frequencies, percentages, means, and standard deviations. The Chi-square test was employed for the analysis of categorical variables. The relationship between knowledge and attitude was established by bivariate correlational analysis.

\section{RESULTS}

A total of 187 nurses completed the questionnaire and attitude scale. The mean age of the participants was $25.6 \pm 4.89$ years, and the majority (84.5\%) were females. As per the professional qualification, $40(21.4 \%)$ participants had done B.Sc. nursing, and the rest had completed their diplomas in general nursing and midwifery. Regarding work experience, 84 (44.9\%) participants had no work experience, and 19 (10.2\%) had an experience of more than ten years (Table 1 ). Only three participants (1.6\%) had attended training related to the prevention and management of skin conditions.

\section{Respondents' Knowledge on Common Skin Diseases}

Most of the participants ( $\mathrm{n}=142 ; 75.9 \%)$ knew that leprosy is a communicable disease. However, only $60(32.1 \%)$ were aware that leprosy classification is based on the number of skin lesions. Nearly one fourth of the participants $(28.3 \%)$ knew about the cardinal features for the diagnosis of leprosy. Table 2 summarizes details regarding knowledge on the etiology of common skin disorders.

A per the questions about the basic understanding of dermatology, $88(47.1 \%)$ and $128(68.4 \%)$ of the 
Table 1: Sociodemographic profile, professional qualification, and work experience of the participating nurses $(n=187)$.

\begin{tabular}{|c|c|c|c|}
\hline S.No & Variable & $\mathbf{f}$ & $\%$ \\
\hline \multirow[t]{4}{*}{1.} & Age (in yrs.) & & \\
\hline & $21-30$ & 158 & $(84.5)$ \\
\hline & $31-40$ & 26 & (13.9) \\
\hline & $>40$ & 3 & $(1.6)$ \\
\hline \multirow[t]{3}{*}{2.} & Sex & & \\
\hline & Male & 29 & $(15.5)$ \\
\hline & Female & 158 & $(84.5)$ \\
\hline \multirow[t]{4}{*}{3.} & Marital status & & \\
\hline & Never married & 149 & $(79.7)$ \\
\hline & Currently married & 37 & (19.8) \\
\hline & Divorced & 1 & $(0.5)$ \\
\hline \multirow[t]{6}{*}{4.} & Per capita income (BG Prasad scale) & & \\
\hline & 7008 and above (upper class) & 104 & $(55.6)$ \\
\hline & 3504-7007 (upper-middle class) & 57 & (30.5) \\
\hline & 2102-3503 (middle class) & 15 & (8) \\
\hline & 1051-2101 (lower-middle class) & 9 & (4.8) \\
\hline & Below 1050 (lower class) & 2 & (1.1) \\
\hline \multirow[t]{3}{*}{5.} & Professional education & & \\
\hline & GNM & 147 & (78.6) \\
\hline & B.Sc. nursing & 40 & $(21.4)$ \\
\hline \multirow[t]{5}{*}{6.} & Work experience & & \\
\hline & No experience & 84 & 44.9 \\
\hline & $<5$ yrs. & 66 & 35.3 \\
\hline & $5-10$ yrs. & 18 & 9.6 \\
\hline & $>10$ yrs. & 19 & 10.2 \\
\hline
\end{tabular}

nurses knew the characteristic features of papules and vesicles, respectively, while the question about lichenification was answered correctly only by $17.6 \%$. The characteristics of urticaria were known to $66.8 \%$, while $58.8 \%$ and $28.9 \%$ could correctly identify fungal infections and psoriasis, respectively, from the photographs.

Nearly one fifth ( $\mathrm{n}=41 ; 21.9 \%)$ of the participating nurses were aware that clotrimazole cream is the treatment of choice for treating fungal infections of the skin, whereas 59 (31.6\%) knew that topical steroids should not be used for the treatment of acne vulgaris. Most nurses ( $\mathrm{n}=134 ; 71.7 \%)$ were correct about permethrin being the treatment of choice for scabies. Nearly three fourth ( $\mathrm{n}=142 ; 75.9 \%$ ) correctly answered the question about the nursing management of drug rash (Table 2).

The mean and SD of the knowledge scores in the study were $10.7 \pm 2.2$. Nearly two thirds $(n=116 ; 62 \%)$ of the subjects demonstrated a low level of knowledge, and the remaining 77 (38\%) demonstrated a moderate level of knowledge. There was no participant with a high level of knowledge.

\section{Respondents' Attitudes}

A five-point Likert scale was used to assess the nurses' attitudes toward common skin conditions and their involvement in managing these. A majority of the nurses
Table 2: The nurses' knowledge on common skin conditions $(n=187)$.

\begin{tabular}{|c|c|c|}
\hline S.No & Item of Knowledge & $\begin{array}{c}\text { Correct } \\
\text { Responses (\%) }\end{array}$ \\
\hline 1 & Leprosy is a communicable disease. & $142(75.9)$ \\
\hline 2 & $\begin{array}{l}\text { Psoriasis is a chronic inflammatory skin } \\
\text { disorder in which epidermal cells proliferate } \\
\text { abnormally fast. }\end{array}$ & $90(48.1)$ \\
\hline 3. & $\begin{array}{l}\text { Clotrimazole cream is the treatment of choice } \\
\text { for treating fungal infections of the skin. }\end{array}$ & $41(21.9)$ \\
\hline 4. & $\begin{array}{l}\text { A papule is an elevated spot; a palpable, firm, } \\
\text { and circumscribed lesion generally }<5 \mathrm{~mm} \text { in } \\
\text { diameter. }\end{array}$ & $88(47.1)$ \\
\hline 5. & $\begin{array}{l}\text { An elevated, circumscribed, superficial, and } \\
\text { fluid-filled blister }<5 \mathrm{~mm} \text { in diameter is called } \\
\text { a vesicle. }\end{array}$ & $128(68.4)$ \\
\hline 6 & $\begin{array}{l}\text { Rough and thickened epidermis and } \\
\text { accentuated skin markings caused by rubbing } \\
\text { or scratching are called lichenification. }\end{array}$ & $33(17.6)$ \\
\hline 7. & Molluscum contagiosum is a viral disease. & $11(5.9)$ \\
\hline 8. & $\begin{array}{l}\text { There should be }>5 \text { lesions for the diagnosis } \\
\text { of multibacillary leprosy. }\end{array}$ & $109(58.3)$ \\
\hline 9. & Cardinal features for the diagnosis of leprosy. & $53(28.3)$ \\
\hline 10. & $\begin{array}{l}\text { WHO criteria for the classification of leprosy } \\
\text { are based on the number of skin lesions. }\end{array}$ & $60(32.1)$ \\
\hline 11. & $\begin{array}{l}\text { Permethrin is the treatment of choice for } \\
\text { scabies. }\end{array}$ & $134(71)$ \\
\hline 12. & Tinea cruris is caused by a fungus. & $145(77.5)$ \\
\hline 13. & Tinea capitis is caused by dermatophytes. & 56 (29.9) \\
\hline 14. & Pyoderma is caused by a bacterium. & $123(65.8)$ \\
\hline 15. & $\begin{array}{l}\text { Obesity, foods with a high glycemic index, and } \\
\text { stress are the risk factors for acne. }\end{array}$ & $153(81.8)$ \\
\hline 16. & $\begin{array}{l}\text { Topical steroids are not used in the treatment } \\
\text { of acne. }\end{array}$ & $59(31.6)$ \\
\hline 17. & $\begin{array}{l}\text { Acute urticaria is characterized by a red rash } \\
\text { all over the body, swelling of the lips, and } \\
\text { difficulty in breathing. }\end{array}$ & $125(66.8)$ \\
\hline 18. & $\begin{array}{l}\text { Stopping the suspected drug is the most } \\
\text { crucial step in the nursing management of } \\
\text { drug rash. }\end{array}$ & $142(75.9)$ \\
\hline 19. & $\begin{array}{l}\text { Correct diagnosis of tinea corporis from a } \\
\text { photograph. }\end{array}$ & $110(58.8)$ \\
\hline 20. & $\begin{array}{l}\text { Correct diagnosis of psoriasis from a } \\
\text { photograph. }\end{array}$ & $54(28.9)$ \\
\hline
\end{tabular}

$(\mathrm{n}=152 ; 81.3 \%)$ agreed and strongly agreed to the statement that they had studied dermatology during their basic nursing education training. Still, only 58 (31\%) were satisfied with the dermatology content in the nursing curriculum. Only 51 (27.3\%) felt confident performing skin examinations of patients, although 77 (41.2\%) agreed that they were adequately trained in the diagnosis and management of common skin conditions during nursing training. Regarding the nurses' willingness to be involved in the management of common skin diseases, most of the nurses $(n=146 ; 78 \%)$ agreed and strongly agreed with the statement. Nearly $81 \%$ agreed that nurses should also perform skin examinations. A majority ( $\mathrm{n}=$ $155 ; 82.9 \%$ ) did not consider lack of time as a reason for not performing skin examinations. 
Nearly half of the nurses ( $\mathrm{n}=93 ; 49.7 \%)$ disagreed and strongly disagreed that most skin diseases are communicable. Half (50.3\%) felt confident in taking care of patients with any skin condition, whereas $65.8 \%$ disagreed that they were afraid of taking care of patients with skin disorders as they are contagious. Only $51(27.3 \%)$ agreed that they were confident in diagnosing common skin conditions. A majority of the subjects (85.6\%) agreed and strongly agreed to the question about their willingness to learn more about dermatology and to attend continuing education courses and lectures for the diagnosis and management of common skin conditions.

The median attitude score of the participants was 43 (IQR: 40-46). Most of the nurses (76.2\%) scored above the median, demonstrating their positive attitude and willingness to undertake the task.

The association of knowledge and attitude scores with selected variables was assessed with a chi-square test. The results showed no significant association of knowledge scores with age, sex, professional qualification, and years of experience. However, there was a positive association between knowledge scores and attitude.

\section{DISCUSSION}

Skin diseases are associated with significant morbidity and the psychosocial and emotional issues in individuals suffering from skin conditions are comparable to that of arthritis, back pain, diabetes mellitus, epilepsy, cancer, and even asthma $[15,16]$. Skin diseases are highly common in rural and urban areas, yet there is a shortage of well-trained dermatologists who may address the needs of these problems [17]. Most dermatologists work in urban areas, whereas almost $70 \%$ of India's population lives in rural areas [18]. Hence, task shifting is the need of the hour for addressing this supply and demand imbalance in skin disorders, and nurses are the ideal choice as they are one of the vital health care providers in any health setup [11]. Adequate knowledge and a favorable attitude are prerequisites for effective and successful task shifting in any specialty. The current study was conducted in a nurses' training institute in Northern India. It was aimed to generate useful outputs that may support future actions to improve the knowledge and attitude of nurses involved in dermatological care. Although there exist numerous skin disorders, we selected the most common skin conditions prevalent in India to assess the participants' knowledge [2,19].

A study by Kouotou et al. assessed the knowledge, attitudes, and practices of medical personnel regarding atopic dermatitis. Twenty-two percent of the participants were nurses, and $45 \%$ of them showed a moderate level of knowledge, with none in the good level of knowledge category [20]. Although we attempted to study knowledge on dermatology and not a specific disease, our study's findings agree with the findings of the above research, as most of our study participants were also in the low to moderate knowledge category and none were in the good knowledge category.

Dermatological conditions are considered difficult to diagnose and manage, even by primary care physicians and family physicians. In a cross-sectional survey on the primary care physician's ability to recognize common dermatoses, it was observed that the mean score on a photograph quiz was 4.1/10, and $70.5 \%$ of the participants rated their ability to diagnose and manage skin disorders as average, on a five-point Likert scale. The authors believed that primary care physicians had poor knowledge of skin disorders, and there is a need for more training in the diagnosis and management of common dermatological conditions [21]. Federman et al. also concluded that family care physicians cannot diagnose and manage dermatological conditions [22]. Similar findings were revealed in other studies [23,24]. Another study, involving 400 health workers from Mali, revealed inadequate knowledge on skin conditions. Knowledge of health workers on the typical cases of pyoderma, scabies, tinea capitis, and hypochromic patches was assessed by showing pictures on a PowerPoint presentation [25]. The authors reported that $19 \%$ of the subjects showed correct knowledge on the treatment of scabies. We observed that most of the nurses $(71.7 \%)$ knew that permethrin is the treatment of choice for scabies, and $58.8 \%$ could correctly diagnose fungal infections. However, in a study from Mali, only $6 \%$ of health workers could diagnose mycosis. The difference might have been due to various factors, such as different methodologies and data collection instruments and the basic qualification and knowledge of the healthcare workers.

Our study demonstrated a positive attitude and willingness of the nurses to learn and be involved in the management of skin conditions (76\% of the participants). Similar results were reported in a study from Sub-Saharan 
Africa on task shifting for the diagnosis of Kaposi's sarcoma. In this study, physicians, clinical officers, nurses, and technicians were trained by a dermatologist in doing skin punch biopsy. Although initially targeted at physicians, the proportion of skin biopsies done by nurses $(62 \%)$ were more as compared to physicians (15\%), clinical officers (12\%), and technicians (11\%), which suggests nurses' willingness to undertake this task [26].

Although most of the participants in our study agreed to have studied dermatology in their curriculum, only $27.3 \%$ said that they felt confident in performing skin evaluations, and $69 \%$ of the study subjects believed that the dermatology content of their curricula was not enough and should be enhanced with the addition of practical training. Earlier studies showed that training healthcare workers and physicians in the care of skin diseases may be the key to improving knowledge and patient care. A study from Mali showed a marked improvement in the management of skin diseases in primary health care after a single day of training of the healthcare workers [24,25].

The strength of the current study is that it is probably the first study assessing nurses' knowledge and attitudes regarding common skin conditions in India. However, the study also had certain limitations as it was conducted in a single nursing training institute. Therefore, the nurses' knowledge and attitudes may not provide a true picture for all nurses in India. A small sample size also limited the generalizability of the study results. Further studies are needed for a more detailed insight into the assessment of the knowledge and attitudes of nursing students and practicing nurses regarding skin conditions and their management, which will help to formulate future educational content in nursing studies.

\section{CONCLUSION}

Nurses demonstrated a low level of knowledge on the diagnosis and management of common skin conditions, but a majority showed a positive attitude and willingness to learn and care for patients with skin diseases. It is recommended that relevant concepts related to skin conditions should be integrated into nursing curricula, and there should be more emphasis on continuing education.

\section{Statement of Human and Animal Rights}

All the procedures followed were in accordance with the ethical standards of the responsible committee on human experimentation (institutional and national) and with the 2008 revision of the Declaration of Helsinki of 1975.

\section{Statement of Informed Consent}

Informed consent for participation in this study was obtained from all participants.

\section{REFERENCES}

1. GBD 2017 DALYs and HALE Collaborators. Global, regional, and national disability-adjusted life years (DALYs) for 359 diseases and injuries and healthy life expectancy (HALE) for 195 countries and territories, 1990-2017: A systematic analysis for the Global Burden of Disease Study 2017. Lancet. 2018;392:1859-922.

2. GBD 2017 Disease and Injury Incidence and Prevalence Collaborators. Global, regional, and national incidence, prevalence, and years lived with disability for 354 diseases and injuries for 195 countries and territories, 1990-2017: A systematic analysis for the Global Burden of Disease Study 2017. Lancet. 2018;392:1789-858.

3. Global burden of disease study 2017. GBD Compare. Available at https://vizhub.healthdata.org/gbd-compare/ [Accessed on 22.02.2020]

4. Global burden of disease study 2017. GBD India Compare. Available at https://vizhub.healthdata.org/gbd-compare/india [Accessed on 22.02.2020]

5. Resneck J Jr, Kimball AB. The dermatology workforce shortage. J Am Acad Dermatol. 2004;50:50-4.

6. IADVL news. 2020;16:9. https://www.iadvl.org/newsletter.php (last accessed on 06 June 2020)

7. Hay R, Estrada R, Grossmann H. Managing skin disease in resourcepoor environments: The role of community-oriented training and control programs. Int J Dermatol. 2011;50:558-63.

8. Andrews RM, Kearns T, Connors C, Parker C, Carville K, Currie BJ, et al. A regional initiative to reduce skin infections amongst aboriginal children living in remote communities of the Northern Territory, Australia. PLoS Negl Trop Dis. 2009;3:e554.

9. Brown DN, Langan SM, Freeman EE. Task shifting in dermatology:a call to action. JAMA Dermatol. 2017;153:1179-80.

10. Chang AY, Kiprono SK, Maurer TA. Providing dermatological care in resource-limited settings: Barriers and potential solutions. $\mathrm{Br} \mathrm{J}$ Dermatol. 2017;177:247-8.

11. Kavita, Narang T, Dogra S. Task shifting in dermatology: Nurses' role. Indian J Dermatol Venereol Leprol. 2021;87:323-5.

12. Lawton S. The specialist dermatology nurse: Providing expert care to patients. Br J Nurs. 2020;29:136-8.

13. ShuklaLK, PatelRN,PatelSV,BaxiRK. Evaluation of the effect of block level awareness campaign on performanceindicators of nationalleprosy elimination program in Vadodara district, Gujarat, India. Indian J Dermatol Venereol Leprol. 2015;81:257-62.

14. Moola S, Bhaumik S, Nambiar D. Mid-level health providers (MLHPs) for primary healthcare. New Delhi: The George Institute for Global Health, India. 2019.

15. World Health Organization: Epidemiology and Management of Common Skin Diseasesin children in Developing Countries Geneva, World Health Organization. 2005. (https://www.who.int/ maternal_child_adolescent/documents/fch_cah_05_12/en/)

16. Dalgard FJ, Gieler U, Tomas-Aragones L, Lien L, Poot F, Jemec GBE, et al. The psychological burden of skin diseases: A cross-sectional multicenter study among dermatological out-patients in 13 European countries. J Invest Dermatol. 2015;135:984-91.

17. Seth D, Cheldize K, Brown D, Freeman EF. Global burden of skin disease: Inequalities and innovations. Curr Dermatol Rep. 2017;6:204-10.

18. The World Bank. Rural population (\% of total population) - India. 
Available from:https://data.worldbank.org/indicator/SP.RUR. TOTL.ZS?locations=IN (last accessed on 28-07-21).

19. Rao PN, Suneetha S. Current situation of leprosy in india and its future implications. Indian Dermatol Online J. 2018;9:83-9.

20. Kouotou EA, Nansseu JR, Ngangue Engome AD, Tatah SA, Zoung-Kanyi Bissek AC. Knowledge, attitudes and practices of the medical personnel regarding atopic dermatitis in Yaoundé, Cameroon. BMC Dermatol. 2017;17:1.

21. Thakkar SH, Chavda PD, Mehta KG. Do primary care physicians require training in core clinical dermatology? A cross-sectional needs assessment study from Western India. Indian J Dermatol Venereol Leprol. 2019;85:380-7.

22. Federman DG, Kirsner RS. The abilities of primary care physicians in dermatology: Implications for quality of care. Am J Manag Care. 1997;3:1487-92.

23. Nawaz S, Tapley A, Davey AR, van Driel ML, Fielding A, Holliday EG, et al. Management of a chronic skin disease in primary care: An analysis of early-career general practitioners' consultations involving psoriasis. Dermatol Pract Concept. 2021;11:e2021055.
24. Mohan GC, Molina GE, Stavert R. Store and forward teledermatology improves dermatology knowledge among referring primary care providers: A survey-based cohort study. J Am Acad Dermatol. 2018;79:960-1.

25. Mahe A, Faye O, N'Diaye HT, Konaré HD, Coulibaly I, Kéita S, et al. Integration of basic dermatological care into primary health care services in Mali. Bull World Health Organ. 2005;83:935-41.

26. Laker-Oketta M, Wenger M, Semeere A, Castelnuovo B, Lukande R, Asirwa FC, et al. Task shifting and skin punch for the histologic diagnosis of Kaposi's sarcoma in sub-Saharan Africa: A public health solution to a public health problem. Oncology. 2015;89:60-5.

Copyright by Kavita Kavita, et al. This is an open-access article distributed under the terms of the Creative Commons Attribution License, which permits unrestricted use, distribution, and reproduction in any medium, provided the original author and source are credited.

Source of Support: Nil. Conflict of Interest: None declared. 